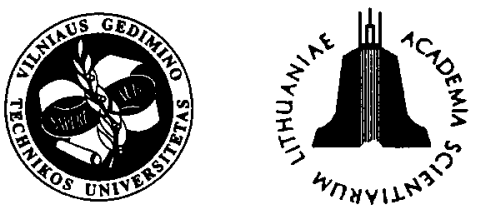

JOURNAL OF CIVIL ENGINEERING AND MANAGEMENT

http:/www.vtu.lt/english/editions

2002, Vol VIII, No 3, 164-168

\title{
DEFLECTION OF FLEXURAL REINFORCED CONCRETE STRUCTURES WITH EXTERNAL NON-METALLIC REINFORCEMENT (EXPERIMENTAL AND THEORETICAL INVESTIGATION)
}

\author{
Juozas Valivonis \\ Dept of Reinforced Concrete and Masonry Structures, Vilnius Gediminas Technical University, \\ Sauletekio al. 11, LT-2040 Vilnius. E-mail: gelz@st.vtu.lt
}

Received 07 Feb 2002; accepted 12 June 2002

\begin{abstract}
In many cases concrete structures with prestressed steel being sufficiently strong do not meet requirements for stiffness. It is possible to avoid steel prestressing in concrete structures by means of providing additional non-metallic reinforcement, which gives opportunity to increase stiffness of beams significantly. Experimental investigations of reinforced concrete beams with external non-metallic reinforcement were made. Method for calculation of deflection of beams with external non-metallic reinforcement is presented in this article. Theoretical calculations of deflections using the proposed method were performed. Sufficiently good agreement with experimental deflection values was obtained.
\end{abstract}

Keywords: reinforced concrete structures, external non-metallic reinforcement, beams, deflection, experimental stiffness, deflection calculation.

\section{Introduction}

In many cases reinforced concrete structures with steel bar reinforcement meet strength requirements but do not meet requirements for stiffness. Therefore it is necessary to prestress bar reinforcement or to increase cross-sectional dimensions of such structures.

Stiffness can be increased without prestressing during manufacture of concrete structures by the use of additional external non-metallic reinforcement and increased substantially [1-14]. In these references different effect of non-metallic reinforcement on deflections has been obtained. This influence is mainly determined by the type and physical-mechanical characteristics of non-metallic reinforcement. The external reinforcement can include glass plastic plates, carbon plastic strips, fibre reinforced concrete plates, polymer concrete or eternity plates, etc.

External non-metallic reinforcement can be fixed to the concrete by adhesion between reinforcing material and concrete, or glue.

In most applications of non-metallic reinforcement there is no slip between concrete and external reinforcement.

Many authors in their investigations of composite structures with external non-metallic reinforcement dealt with analysis of strength and crack resistance $[2-5,8,9$, $13,15]$. Investigation [4] deals with calculation of deflections.

\section{Method for curvature calculation of flexural mem- bers with external non-metallic reinforcement}

It is proposed for calculation of deflection of flexural reinforced concrete members with external non-metallic reinforcement to assume that strains in a cross-section imposed by external load vary linearly (the hypothesis of plane cross-sections is valid). Stress and strain relationship for concrete is described by the following formula proposed by the European Concrete Committee

$$
\sigma_{c}=\begin{gathered}
\varepsilon_{c} \\
\varepsilon_{c 1}
\end{gathered}\left(2-\varepsilon_{c}\right) f_{c 1},
$$

where $\varepsilon_{c l}$ is the ultimate concrete strain (when $\sigma_{c}=f_{c}$ ), $\varepsilon_{c}$ - concrete strain at any loading level.

Concrete tensile strain

$$
\varepsilon_{c t u}=c f_{c t} E_{c} .
$$

Design stress and strain distribution assumed for calculation of curvature of reinforced concrete members with external non-metallic reinforcement is presented in Fig 1.

Curvature of these members is determined by wellknown relationship

$$
\frac{1}{r}=\begin{aligned}
& \varepsilon_{c m}+\varepsilon_{e m}, \\
& h+0,5 d_{e}
\end{aligned}
$$

where $\varepsilon_{c m}$ and $\varepsilon_{e m}$ are average values of strains in concrete and external non-metallic reinforcement, $d_{e}$ - thickness of external reinforcement layer. 


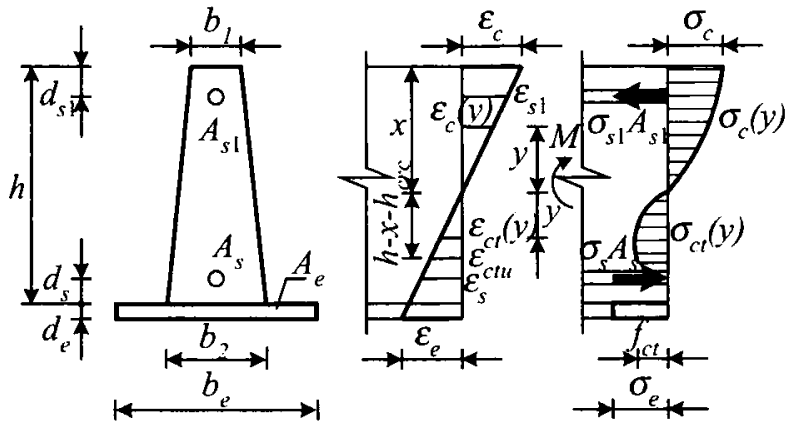

Fig 1. Design state of stresses in reinforced concrete beams with external non-metallic reinforcement for calculation of deflections

Average and compression concrete external reinforcement strains can be expressed as follows:

$$
\varepsilon_{c m}=\psi_{c} \varepsilon_{c} \text { and } \varepsilon_{e m}=\psi_{e} \varepsilon_{e} .
$$

Strains in bar reinforcement, external non-metallic reinforcement and in any layer of concrete cross-section are determined by such formulae:

$$
\begin{gathered}
\varepsilon_{s}=\varepsilon_{c}\left(h-x-d_{s}\right) / x ; \\
\varepsilon_{e}=\varepsilon_{c}\left(h-x+0,5 d_{e}\right) x ; \\
\varepsilon_{c}(y)=\varepsilon_{c} \cdot y x .
\end{gathered}
$$

Strain in the layer under the greatest compression is

$$
\varepsilon_{c}=\begin{gathered}
c \cdot f_{c t} \cdot x \\
E_{c}\left(h-x-h_{c r c}\right)
\end{gathered},
$$

where $h_{c r c}$ is the height of crack in concrete under tension.

Taking into account the relationships presented above, average compression concrete $\varepsilon_{c m}$ and external reinforcement $\varepsilon_{e m}$ strain can be presented by formulae (9) and (10).

$$
\begin{gathered}
\varepsilon_{c m}=\frac{c \psi_{c} f_{c t} x}{E_{c}\left(h-x-h_{c r c}\right)} ; \\
\varepsilon_{e m}=\frac{c \psi_{e} f_{c t}\left(h-x+0,5 d_{e}\right)}{E_{c}\left(h-x-h_{c r c}\right)}
\end{gathered}
$$

By the results of experiments with reinforced concrete members with external non-metallic reinforcement it has been established that coefficient $\psi_{c}=0,93$.

Expression (11) is proposed for determining coefficient $\psi_{e}$.

$$
\psi_{e}=0,948+0,034 \lg \left(\begin{array}{l}
b_{e} \\
b_{2}
\end{array}\right)-0,04\left(\begin{array}{c}
M \\
M_{u e}
\end{array}\right),
$$

where $b_{e}$ and $b_{2}$ are widths of non-metallic reinforcement and of reinforced member web; $M$ and $M_{u e}{ }^{-}$ bending moments imposed by external load and the moment when external reinforcement is about to break.

The height of crack can be determined from condition of equilibrium of moments taken about the neutral axis.

$$
\begin{aligned}
& \int_{0}^{x} \sigma_{c}(y) b(y) y d y+\sigma_{s 1} A_{s 1}\left(x-d_{s 1}\right)+\int_{0}^{h-x-h_{c r c}} \sigma_{c t}(y) b(y) y d y+ \\
& +\sigma_{s} A_{s}\left(h-x-d_{s}\right)+\sigma_{e} A_{e}\left(h-x-0,5 d_{e}\right)-M=0 .
\end{aligned}
$$

Equation (12) can be presented in this way:

$$
\begin{aligned}
& \underset{h-x-h_{c r c}}{c f_{c t}}\left\{\begin{array}{c}
f_{c} \\
E_{c} \varepsilon_{c 1}
\end{array}\left[2 I_{c}-\frac{c f_{c t} J_{c}}{E_{c} \varepsilon_{c 1}\left(h-x-h_{c r c}\right)}\right]+\right. \\
& \left.+I_{c t, c r c}-\begin{array}{c}
0,25 \cdot c \cdot J_{c t, c r c} \\
h-x-h_{c r c}
\end{array}+\alpha_{s 1} I_{s \mathrm{l}}+\alpha_{s} I_{s}+\alpha_{e} I_{e}\right\}-M=0 \text {, }
\end{aligned}
$$

where $I_{c t, c r c}$ is the second moment of tension concrete area above the crack in respect of the neutral axis,

$$
J_{\text {ct.crc }}=\int_{0}^{h-x-h_{c r c}} b(y) y^{3} d y .
$$

Using the iterative method from equation (13) the height $h_{c r c}$ of normal crack in concrete tension zone is calculated.

Position of the neutral in cross-section is determined by the condition of equilibrium of horizontal forces:

$$
\begin{aligned}
& \int_{0}^{x} \sigma_{c}(y) b(y) d y+\sigma_{s 1} A_{s 1}= \\
& =\int_{0}^{h-x-h_{c r c}} \sigma_{c t}(y) b(y) d y+\sigma_{s} A_{s}+\sigma_{e} A_{e} .
\end{aligned}
$$

This condition of equilibrium can be rearranged into such expression:

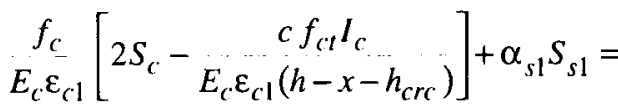

$$
\begin{aligned}
& =S_{c t, c r c}-\frac{0,25 \cdot c \cdot I_{c t, c r c}}{h-x-h_{c r c}}+\alpha_{s} S_{s}+\alpha_{e} S_{e} .
\end{aligned}
$$

\section{Experimental investigations of flexural members with external non-metallic reinforcement}

In laboratory, 15 reinforced concrete beams with external non-metallic reinforcement were tested. Beams were of variable cross-section width. Their dimensions were $70(100) \times 250 \times 2600 \mathrm{~mm}$. The following beams were tested: two series of beams with external reinforcement (Fig 2) and control beams: Bl - beams with $100 \mathrm{~mm}$ wide external non-metallic reinforcement; B2 - beams with $200 \mathrm{~mm}$ wide external non-metallic reinforcement; BK - control beams without external reinforcement.

Concrete of B25 class was used for the beams. Average tension strength of external non-metallic reinforcement $f_{e, m}=14,56 \mathrm{MPa}$, modulus of elasticity $E_{e}=2400 \mathrm{MPa}$. In the tension zone beams were reinforced with $\varnothing 16$ AllI class steel bars, the average yield limit of which $\sigma_{y}=444,8 \mathrm{MPa}$. 


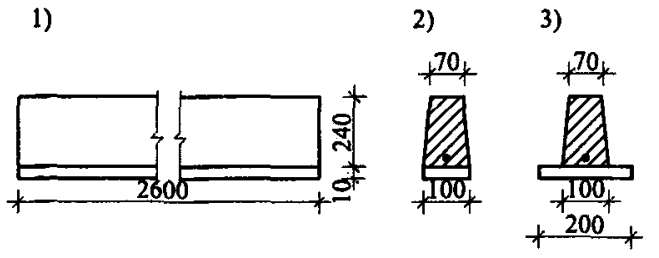

Fig 2. Experimental specimens: 1 - general view, 2 - beam $\mathrm{B} 1,3$ - beam $\mathrm{B} 2$

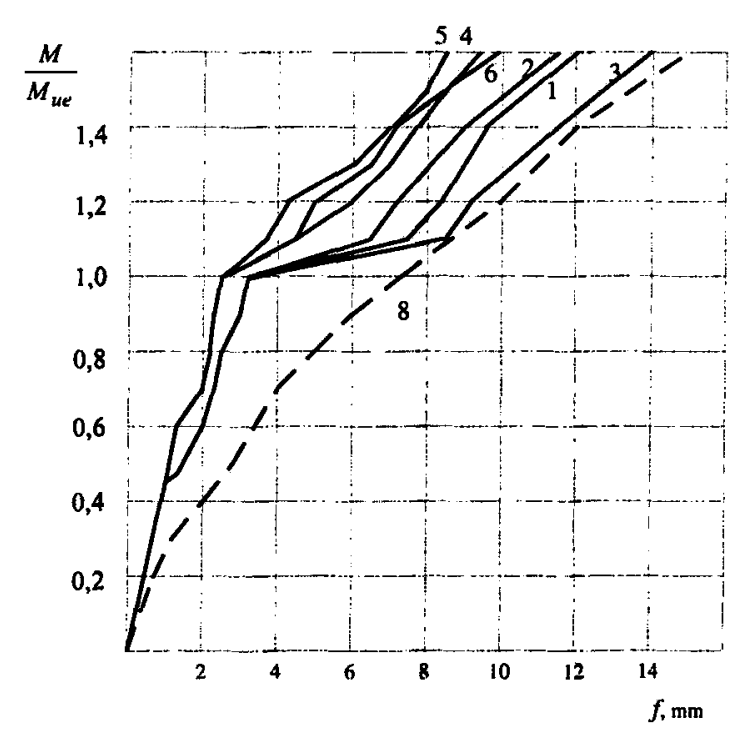

Fig 3. Experimental deflections of $B 1$ and $B K 1$ beams: 1 - B1-1; 2 - B1-2; 3 - B1-3; 4 - B1-4; 5 - B1-5; 6 $\mathrm{B} 1-6 ; 7-\mathrm{B} 1-1 ; 8-\mathrm{BK} 1$ beams

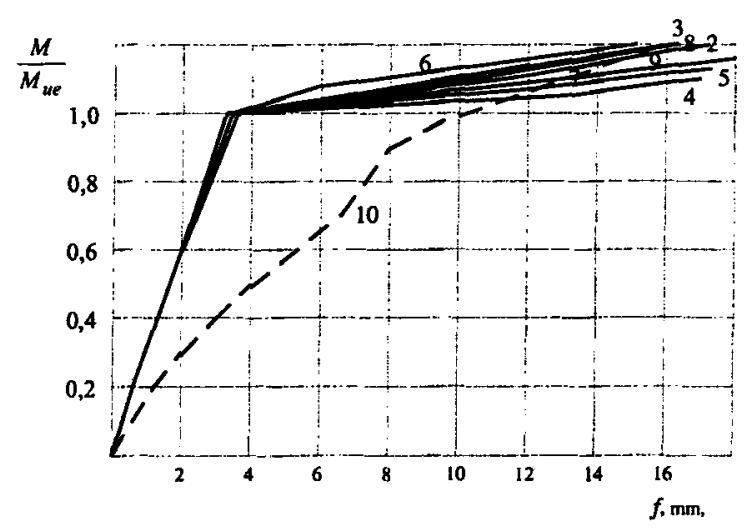

Fig 4. Experimental deflections of $\mathrm{B} 2$ and $\mathrm{BK} 2$ beams: 1 - B2-1; 2 - B2-2; 3 - B2-3; 4 - B2-4; 5 - B2-5; 6 $\mathrm{B} 2-6 ; 7$ - B2-7; 8 - B2-8; 9 - B2-9; 10 - BK2 beams
During tests deflections of beams were recorded, the values of which are presented in Figs 3, 4 .

Experimental investigations indicated that external non-metallic reinforcement substantially reduces deflection of flexural members at the same load level. Deflections of such members increase with load linearly until the external reinforcement breaks. In case of $200 \mathrm{~mm}$ wide strips $\left(\mu_{e}=10 \%\right)$ cracks in concrete did not effect the deflection increase rate.

External non-metallic reinforcement behaved in an elastic way. Stresses in the cross-section via cracking were distributed between adjacent cross-sections. Because of this crack the width and its influence on deflections were substantially reduced. Increase in quantity of external reinforcement leads to reducing deflections of beams until the external reinforcement breaks. Deflections of beams (B1 series) with $100 \mathrm{~mm}$ wide external reinforcement reduced 1,75-2,03 times in comparison with deflections of control beams, and for beams with $200 \mathrm{~mm}$ wide external reinforcement this reduction was $2,0-2,95$ times.

Deflections substantially increased when external non-metallic reinforcement broke and became equal to or greater than deflections of control beams (Figs 3,4).

\section{Calculation of theoretical deflections and compari- son with experimental values}

Theoretical deflection values were calculated using the method described in this article. Deflections were calculated due to the action of bending moment $M=M_{c r c}+\left(M_{u e}-M_{c r c}\right) 2$ and due to that at the stage of incipient breakage of external reinforcement exernal reinforcement $\left(M_{u e}\right)$.

Calculations were performed taking into account the average strength characteristics of concrete and steel bar reinforcement as well as actual geometrical characteristics of beams (Table 1). Calculation results are presented in Table 2.

Deflections of beams with external non-metallic reinforcement were compared with their theoretical values. The difference between experimental and theoretical values of deflections of beams subjected to bending moment $M=M_{c r c}+\left(M_{u e}-M_{c r c}\right) 2$ was up to $9 \%$ and this difference at the stage of incipient breakage of external reinforcement was up to $8 \%$ (with exception of B2-7 beams) (Table 2).

\section{Conclusions}

Application of external non-metallic reinforcement makes it possible to avoid prestressing of steel reinforcement to provide a required stiffness of structures.

Experimental investigations have indicated that due to external non-metallic reinforcement the deflection of beams is reduced by $1,75-2,03$ times when percentage 
Table 1. Dimensions of beam specimens and mean strength values of concrete

\begin{tabular}{|c|c|c|c|c|c|c|c|}
\hline Beam & $b_{1}, \mathrm{~m}$ & $b_{2}, \mathrm{~m}$ & $b_{\ell}, \mathrm{m}$ & $h, \mathrm{~m}$ & $f_{\text {cmm }}, \mathrm{MPa}$ & $f_{i t, m}, \mathrm{MPa}$ & $E_{\text {cmm }}, \mathrm{MPa}$ \\
\hline $\mathrm{B} 1-1$ & 0,684 & 0,09 & 0,099 & 0,245 & 28,72 & 1,75 & 28000 \\
\hline $\mathrm{B} 1-2$ & 0,692 & 0,1015 & 0,103 & 0,245 & 28,72 & 1,75 & 28000 \\
\hline $\mathrm{B} 1-3$ & 0,733 & 0,108 & 0,100 & 0,247 & 28,72 & 1,75 & 28000 \\
\hline $\mathrm{B} 1-4$ & 0,695 & 0,090 & 0,101 & 0,245 & 27,25 & 1,78 & 29000 \\
\hline $\mathrm{B} 1-5$ & 0,737 & 0,1085 & 0,102 & 0,248 & 27,25 & 1,78 & 29000 \\
\hline B1-6 & 0,722 & 0,104 & 0,101 & 0,247 & 27,25 & 1,78 & 29000 \\
\hline B2-1 & 0,725 & 0,103 & 0,220 & 0,241 & 28,5 & 2,59 & 30700 \\
\hline B2-2 & 0,0680 & 0,096 & 0,215 & 0,243 & 28,5 & 2,59 & 30700 \\
\hline B2-3 & 0,0741 & 0,110 & 0,199 & 0,243 & 28,5 & 2,59 & 30700 \\
\hline B2-4 & 0,0705 & 0,090 & 0,201 & 0,245 & 31,1 & 2,72 & 30700 \\
\hline B2-5 & 0,0719 & 0,1042 & 0,200 & 0,244 & 31,1 & 2,72 & 30700 \\
\hline B2-6 & 0,0740 & 0,1085 & 0,200 & 0,244 & 31,1 & 2,72 & 30700 \\
\hline B2-7 & 0,0681 & 0,094 & 0,200 & 0.248 & 26,65 & 2,71 & 31000 \\
\hline B2-8 & 0,0720 & 0,1028 & 0,200 & 0,249 & 26,65 & 2,71 & 31000 \\
\hline B2-9 & 0,0740 & 0,1101 & 0,200 & 0,247 & 26,65 & 2,71 & 31000 \\
\hline
\end{tabular}

Table 2. Experimental and theoretical beam deflections

\begin{tabular}{|c|c|c|c|c|c|c|}
\hline \multirow{2}{*}{ Beam } & \multicolumn{2}{|c|}{ Deflections at $M=M_{\text {crc }}+\left(M_{\text {ue }}-M_{\text {crc }}\right) / 2$} & \multicolumn{3}{c|}{ Deflection at incipient breakage of external reinforcement $M_{\text {ul }}$} \\
\cline { 2 - 7 } & $f_{\text {ohs }}, \mathrm{mm}$ & $f_{\text {cull }}, \mathrm{mm}$ & $f_{\text {cal }} / f_{\text {obs }}$ & $f_{\text {ribs }}, \mathrm{mm}$ & $f_{\text {cal }}, \mathrm{mm}$ & $f_{\text {cal }} / f_{\text {obs }}$ \\
\hline B1-1 & 2,30 & 2,39 & 1,04 & 3,05 & 3,26 & 1,07 \\
\hline B1-2 & 2,22 & 2,44 & 1,09 & 2,95 & 3,15 & 1,07 \\
\hline B1-3 & 2,33 & 2,45 & 1,05 & 3,04 & 3,28 & 1,08 \\
\hline B1-4 & 2,11 & 2,11 & 1,00 & 2,52 & 2,58 & 1,02 \\
\hline B1-5 & 1,95 & 2,03 & 1,04 & 2,40 & 2,57 & 1,07 \\
\hline B1-6 & 2,24 & 2,15 & 0,96 & 2,50 & 2,57 & 1,03 \\
\hline B2-1 & 2,59 & 2,71 & 1,04 & 3,34 & 3,46 & 1,03 \\
\hline B2-2 & 2,75 & 2,74 & 0,99 & 3,46 & 3,43 & 0,99 \\
\hline B2-3 & 2,60 & 2,73 & 1,05 & 3,39 & 3,51 & 1,03 \\
\hline B2-4 & 2,72 & 2,83 & 1,04 & 3,64 & 3,76 & 1,03 \\
\hline B2-5 & 2,74 & 2,92 & 1,06 & 3,20 & 3,69 & 1,15 \\
\hline B2-6 & 2,78 & 2,94 & 1,06 & 3,54 & 3,82 & 1,08 \\
\hline B2-7 & 2,51 & 2,74 & 1,09 & 3,20 & 3,39 & 1,06 \\
\hline B2-8 & 2,70 & 2,75 & 1,02 & 3,45 & 3,51 & 1,02 \\
\hline B2-9 & 2,73 & 2,80 & 1,02 & 3,40 & 3,40 & 1,0 \\
\hline
\end{tabular}

of this reinforcement $\mu=A_{e} / A_{c}=5 \%$ and $2,04-3,04$ times when this percentage $\mu=10 \%$.

When external non-metallic reinforcement is used, influence of cracks in tension zone on deflections of structures is reduced substantially. The calculation method proposed in this article gives an opportunity to determine deflections of composite structures with external non-metallic reinforcement with sufficient accuracy.

\section{References}

1. Vasiljev E. B. Reinforced concrete bridge decks with damp course (Пролетные строения железобетонных мостов с гидрозащитным слоем). Moscow: Transport, 1982. 94 p (in Russian).

2. Bondarenko V. M., Shagin A. L. Design of effective multicomponent structures (Расчет зффективных многокомпонентных конструкций). Moscow: Strojizdat, 1987. $174 \mathrm{p}$ (in Russian).
3. Salija G. Sh., Shagin A. L. Concrete structures with nonmetallic reinforcement (Бетонные конструкции с неметаллическим армированием). Moscow: Strojizdat, 1990. $143 \mathrm{p}$ (in Russian).

4. Kuriger Rex J., Shad Sargond M., Ryan Ball and Khairul Alam M. Analysis of Composite Reinforced Concrete Beams. www.ent.ohion.edu/kuriger/rcbeams.pdf

5. Testing of full-size reinforced concrete beams strengthened with FRP composites: experimental results and design methods verification. Final Report SPR 387. Oregon State University, 2000. 26 p.

6. Nitereka C., Neale K. Analysis of reinforced concrete beams strengthened in flexure with composite laminates. Canadian Journal Civil Engineering. 26 Otava, 1999, p 646-654.

7. Arduini M., Nanni A. Parametric study of beams with externally bonded FRP reinforcement. ACI Structural Journal, 95(5), 1998, p 493-501. 
8. Aleksandra Aprile, Enrico Spacone, Suchart Limkatanym. Role of bond in RC beams strengthened with steel and FRP plates. Journal of Structures Engineering. Vol 127, No 12, 2001 December, p 1445-1452.

9. Juseph M. Tripi, Charles E. Bakis, Thomas E. Boothby, Antonio Nanni. Deformation in concrete with External CFRP Sheet Reinforcement. Journal of Composites for Construction, Vol 4, No 2, May 2000, p 85-94.

10. Mark F. Green, Luke A. Bisby, Yves Beaudion, P. Lebossiere. Effect of freeze-thaw cycles on the bond durability between fibre reinforced polymer plate reinforcement and concrete. Canadian Journal Civil Engineering, 27 Otava, 2000, p 949-959.

11. Mazen M.Almaht, Gyorgy L. Balazs, Kypros Pilakoutas. Strengthening of RC elements by CFRP plate's local failure. 2and Int. PhD Symposium in Civil Engineering, 1998, Budapest.
12. Chajes Michael. Finch William, Januszka Ted, Thomson Theodore. Bond and Force Transfer of Composite Material Plates Bonded to Concrete. ACI Structural Journal, Vol 93, 1996, p 208-217.

13. Saadatmanech H., Malek A. Design guidelines for flexural strengthening of RC beams with FRP plates. Journal Composite for Construction, ASCE, 2(4), 1998, p 158-164.

14. Kalifa A. L., De Lorenzis and Nanni A. FRP Composites for Shear Strengthening of RC Beams. In: Proc., 3rd Inter. Conf. on Advanced Composite Materials in Bridges and Structures. Ottawa, Canada, J. Humer and A. G. Razaqpur, Editors, 15-18 Aug 2000, p 137-144.

15. Valivonis J., Kudzys A., Jurkša A. The resistance of reinforced concrete beams with asbestos cement sheets in the tension zone. Reinforced Concrete Structures (Железобемонные конструкции), No 15. Vilnius, 1987, p 24-36 (in Russian). 